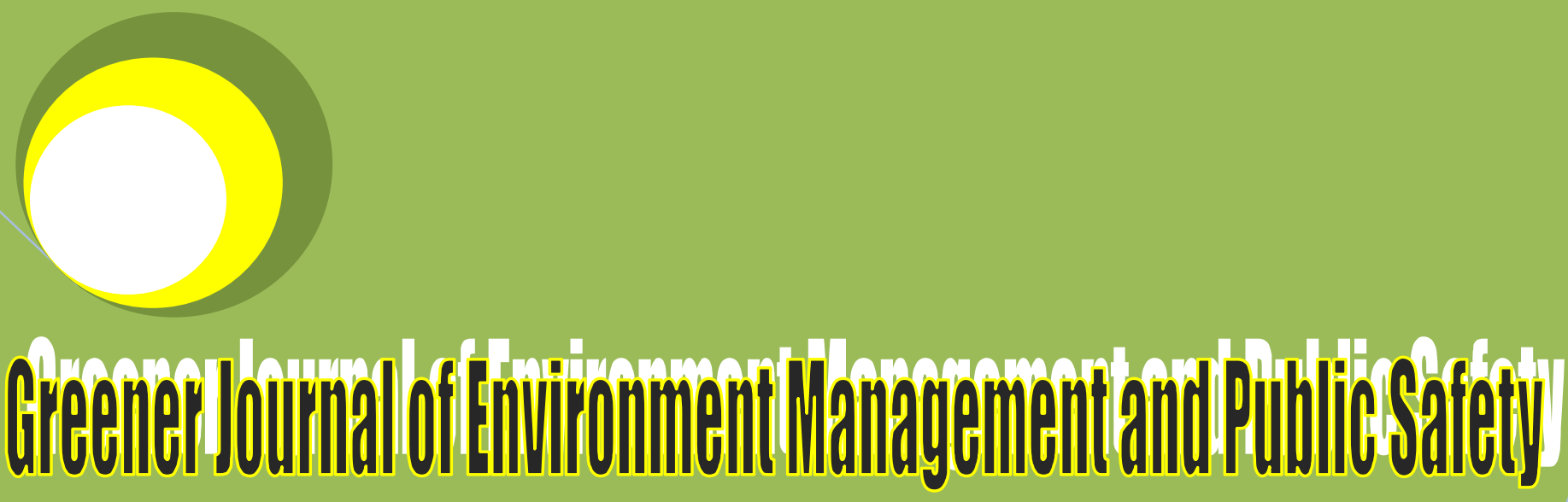

ISSN: 2354-2276

Submitted: 19/07/2016 Accepted: 29/07/2016

Published: 21/08/2016

DOI: http://doi.org/10.15580/GJEMPS.2016.3.071916120

An Investigation of the Spatial Variability of Elements Due to Vinasse Disposal in Waterways at the Albion Bioethanol

Plant, Berbice Guyana

By

Clairmont Clementson Bibi Nariefa Abrahim Oudho Homenauth 


\title{
An Investigation of the Spatial Variability of Elements Due to Vinasse Disposal in Waterways at the Albion Bioethanol Plant, Berbice Guyana
}

\section{Clairmont Clementson ${ }^{1 \star}$, Bibi Nariefa Abrahim², Oudho Homenauth ${ }^{3}$}

\author{
National Agricultural Research and Extension Institute, Mon Repos, East Coast Demerara, Guyana \\ Emails: ${ }^{2}$ narie_abrahim @hotmail .com, ${ }^{3}$ oudhohomenauth @gmail .com \\ *Corresponding Author’s Email: kemba_cc@ yahoo.com
}

\begin{abstract}
The development and diversification of energy sources have recently been given much attention in Guyana. The establishment of the Albion Bioethanol Demonstration Plant is one step forward for the country to achieve a sustainable and green economy. It was observed that the effluent "vinasse" that is discharged from the plant is acidic with high levels of chemical oxygen demand, turbidity, total solids and heavy metals. This study investigated the spatial variability of elements due to vinasse disposal into the main canal that runs through to the sugar factory and meanders into the secondary channels around the cane fields.

Water samples were collected in triplicates at four locations along the canal: (1) point of effluent discharge, (2) five metres, (3) twenty metres and (4) one hundred metres downstream for five different time periods (one week prior, first day of operation, one month after, two months after commencement of the crop and approximately one week after completion of the operation for that season). These samples were analyzed for the following physical and chemical parameters: electrical conductivity, total suspended solids, turbidity, total dissolved solids, $\mathrm{pH}$, chemical oxygen demand, nitrates, orthophosphates, magnesium, aluminum, iron, manganese, copper, cadmium, chromium, cobalt, nickel, lead and zinc. It was determined that continuous disposal of vinasse in the waterway could result in the depletion of the oxygen supply and the accumulation of very toxic levels of heavy metals eventually causing the canal to become uninhabitable for aquatic life. Further, the impact could be detrimental to human life hence it is recommended that studies be conducted on various techniques for the utilization and treatment of this effluent, making it more environmentally friendly.
\end{abstract}

Keywords: vinasse, water quality, waste management, water pollution, bioethanol.

\section{ABBREVIATIONS}

EC: Electrical Conductivity

TSS: Total Suspended Solids

TDS: Total Dissolved Solids

COD: Chemical Oxygen Demand

Mg: Magnesium

Al: Aluminum

Fe: Iron

Mn: Manganese

Cu: Copper

Cd: Cadmium

Cr: Chromium

Co: Cobalt

Ni: Nickel

$\mathrm{Pb}$ : Lead

Zn: Zinc

IARC: International Agency for Research on Cancer 


\section{INTRODUCTION}

The exploration and development of renewable energy sources is one of Guyana's developmental goals. It has been recognized that more practical, cost-effective and efficient energy supplies are crucial for the development of a stronger and sustainable economy. Guided by the Bioenergy policy of Guyana, the Albion Bioethanol Demonstration Plant was commissioned in August of 2013 and aids in the promotion of cleaner and cheaper liquid fuel sources. The bioethanol plant operates in tandem with the sugar factory and utilizes one of its waste product, molasses for the production of $99.9 \% \mathrm{v} / \mathrm{vol}$ of ethanol in a three stage process of fermentation, distillation and dehydration. During the bioethanol production process, an effluent known as "vinasse" is produced. This effluent is released into the main canal that runs through to the sugar factory and meanders into the secondary channels around the cane fields.

Christofoletti et al. (2013) noted that vinasse contains a mixture of organic and inorganic compounds including unconverted sugars, non-fermented carbohydrates and dead yeast. From physical examination, it can be deduced that vinasse has a dark brown colour with a pungent odour. Studies have been conducted on this effluent and it has been observed that vinasse is acidic in nature and has a low electrical conductivity. They also indicated that vinasse has high organic matter content with elevated chemical oxygen demand levels and varying concentrations of heavy metals (Vadivel et al., 2014; Ahmed et al., 2013; Abrahim et al., 2016).

A study conducted by Pereira and Pereira (2008) in Mauritius revealed that vinasse aids in the mobilization of various heavy metals including $\mathrm{Fe}, \mathrm{Cu}, \mathrm{Cd}, \mathrm{Cr}, \mathrm{Ni}, \mathrm{Pb}, \mathrm{Co}$ and $\mathrm{Zn}$. Habeeb et al. (2015) noted that the acidic nature of the vinasse provides a favourable environment for many of these heavy metals to react with water and other elements. However, due to the high organic content of the effluent, the water may become hypoxic. With low oxygen levels, many of the metals will not react with water but rather accumulate over time. This condition can lead to very toxic levels of heavy metals which can be detrimental to both aquatic organisms and humans in the long term (Haiyan et al., 2013). Christofoletti et al. (2013) posited that vinasse caused great damage to the aquatic environment in various parts of Brazil where the effluent was discharged into open waterways. These studies highlight the potential risks involved with the dumping of vinasse into the waterways; therefore this study seeks to assess the spatial distribution of elements due to the dumping of the vinasse in the waterway at the Albion Sugar Estate, Berbice, Guyana.

\section{Research Objectives}

The general aim of this study is to investigate the spatial variability of elements due to the disposal of vinasse in the waterway at the Albion Bioethanol Demonstration Plant. The specific objectives were to:

1. Determine the distribution of the various elements along the waterway from the effluent discharge point.

2. Investigate vinasse's elemental distribution in the canal over time.

3. Evaluate the possible long term environmental impacts of the vinasse discharge in an open water body.

\section{RESEARCH METHODOLOGY}

This study was conducted at the Bioethanol Demonstration Plant within the Albion Sugar Factory Berbice, Guyana. The vinasse from the bioethanol plant is cooled through heat exchangers and then released into the canal that runs through the sugar factory and meanders through the cane fields transporting cane stalks and bagasse.

Water samples were collected at four locations along the waterway; (1) point of effluent discharge, (2) five metres, (3) twenty metres and (4) one hundred metres downstream. About five (5) litres of water samples were collected at the two edges and the center of the canal to form a composite (fifteen (15) litres) water sample for the specific location in buckets. Triplicate samples were collected from the buckets by placing $600 \mathrm{ml}$ bottles into the buckets and filling carefully so as to prevent air bubbles. These water samples were then labeled based on the distance from point of discharge. The samples were placed in cold storage then transported to the Guyana Sugar Corporation's Laboratory, La Bonne Intention, East Coast of Demerara for analysis.

Samples were collected at five time periods. The first set of samples was collected two weeks before the plant commenced operations for the 2015 first crop (February 19, 2015) so as to establish a baseline for the chemical and physical parameters. Samples were also collected on the day the plant commenced operations for that crop (February 27, 2015), one month (March 26) and two months after the plant commenced operations (April 24, 2015), and approximately one week after completion of that crop season (May 28, 2015).

Each water sample was analyzed for electrical conductivity (EC), total suspended solids (TSS), turbidity, total dissolved solids (TDS), pH, chemical oxygen demand (COD), nitrates, orthophosphates, magnesium (Mg), aluminum (Al), iron (Fe), manganese (Mn), copper (Cu), cadmium (Cd), chromium ( $\mathrm{Cr})$, cobalt (Co), nickel (Ni), lead ( P b ) and 
zinc $(\mathrm{Zn})$. These parameters were determined based on the methodology and techniques obtained from the "Standard Methods for the Examination of Water and Wastewater" by the American Public Health Association (1999).

The data was statistically analyzed using the Statistix 9.0 Software where the LSD All Pairwise Comparison Test and Paired T-test were conducted to ascertain statistical difference of element quantity with regards to the time periods for each distance. Further, the data was represented on graphs in Microsoft excel with each parameter being illustrated with respect to both distance and time period.

\section{RESULTS}

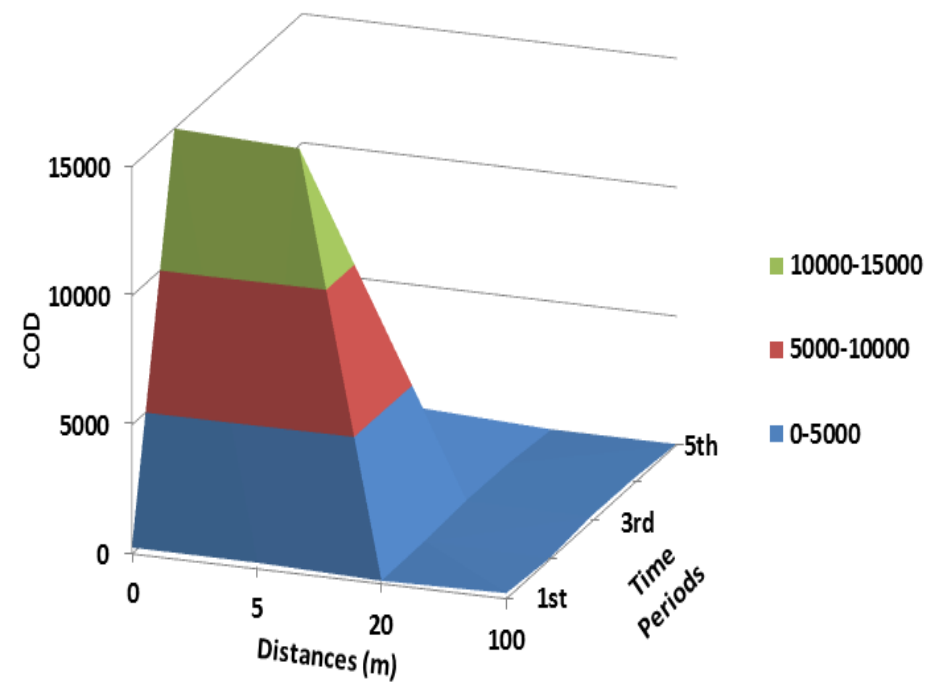

Figure 1: Surface Chart of average COD of water at different distances

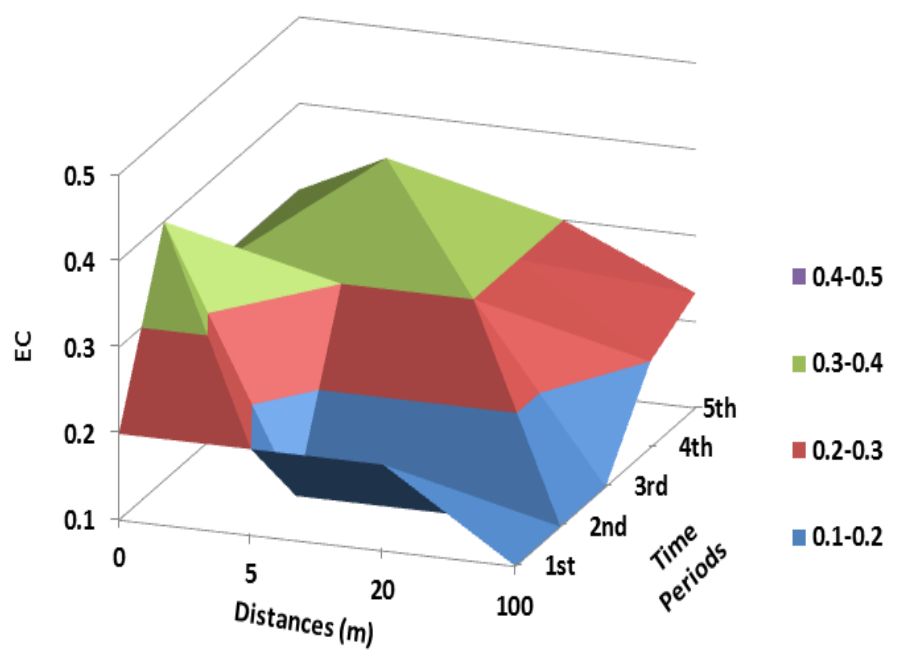

Figure 2: Surface Chart of average EC of water at different distances for five time periods 
Table 1: Physical and chemical composition of vinasse from the Albion Bioethanol plant and two other factories

\begin{tabular}{|c|c|c|c|c|c|c|c|c|c|c|c|c|c|c|c|c|c|}
\hline $\begin{array}{l}\text { Vinasse } \\
\text { Sample }\end{array}$ & Ph & $\begin{array}{l}\text { EC } \\
(\mathrm{mg} / \\
\mathrm{L})\end{array}$ & $\begin{array}{l}\text { Nitrate } \\
\text { (NTU) }\end{array}$ & $\begin{array}{l}\text { Turbidity } \\
\text { (mg/L) }\end{array}$ & $\begin{array}{l}\text { TSS } \\
\text { (mg/L) }\end{array}$ & $\begin{array}{l}\text { COD } \\
\text { (mg/L) }\end{array}$ & $\begin{array}{l}\text { Al } \\
\text { (mg/L) }\end{array}$ & $\begin{array}{l}\text { Co } \\
\text { (mg/L) }\end{array}$ & $\begin{array}{l}\mathrm{Pb} \\
(\mathrm{mg} / \mathrm{L})\end{array}$ & $\begin{array}{l}M g \\
(\mathrm{mg} / \mathrm{L})\end{array}$ & $\begin{array}{l}\mathrm{Ni} \\
(\mathrm{mg} / \mathrm{L})\end{array}$ & $\begin{array}{l}\mathrm{Cr} \\
(\mathrm{mg} / \mathrm{L})\end{array}$ & $\begin{array}{l}\text { Cd } \\
\text { (mg/L) }\end{array}$ & $\begin{array}{l}\text { Mn } \\
(\mathrm{mg} / \mathrm{L})\end{array}$ & $\begin{array}{l}\mathrm{Zn} \\
(\mathrm{mg} / \mathrm{L})\end{array}$ & $\begin{array}{l}\mathrm{Fe} \\
(\mathrm{mg} / \mathrm{L})\end{array}$ & $\begin{array}{l}\mathrm{Cu} \\
(\mathrm{mg} / \mathrm{L})\end{array}$ \\
\hline $\begin{array}{l}\text { Albion } \\
\text { Bioethanol } \\
\text { Plant }\end{array}$ & 4.05 & $\begin{array}{l}17.5 \\
0\end{array}$ & $\mathrm{Nd}$ & 1180.0 & 1150.00 & 49600 & 1.71 & 0.17 & 0.20 & 108 & 0.34 & 0.26 & 0.07 & 5.52 & 1.03 & 602.00 & 0.56 \\
\hline $\begin{array}{l}\text { Kenana } \\
\text { Sugar } \\
\text { Company§ }\end{array}$ & 4.31 & $\begin{array}{l}22.9 \\
0\end{array}$ & 600 & $\mathrm{Nt}$ & 4633.30 & 117000 & 0.01 & $\mathrm{Nt}$ & $\mathrm{Nt}$ & $\mathrm{Nt}$ & $\mathrm{Nt}$ & $\mathrm{Nt}$ & $\mathrm{Nt}$ & 14.00 & $\mathrm{Nt}$ & 17.00 & 86.00 \\
\hline $\begin{array}{l}\text { Kumari \& } \\
\text { Phogat }^{\Phi}\end{array}$ & 4.10 & $\begin{array}{l}22.0 \\
0\end{array}$ & $\mathrm{Nt}$ & $\mathrm{Nt}$ & $\mathrm{Nt}$ & 96000 & $\mathrm{Nt}$ & $\mathrm{Nt}$ & $\mathrm{Nt}$ & $\mathrm{Nt}$ & $\mathrm{Nt}$ & $\mathrm{Nt}$ & $\mathrm{Nt}$ & 0.42 & 0.70 & 12.70 & 0.27 \\
\hline
\end{tabular}

Nt: Not Tested

Nd: Not Detected

§- Ahmed et al. (2012): Physiochemical, Chemical and Microbiological Characteristics of Vinasse, A By-product from the Ethanol Industry

$\Phi$-Vadivel et al (2014): Significance of Vinasse Waste Management in Agriculture and Environment 


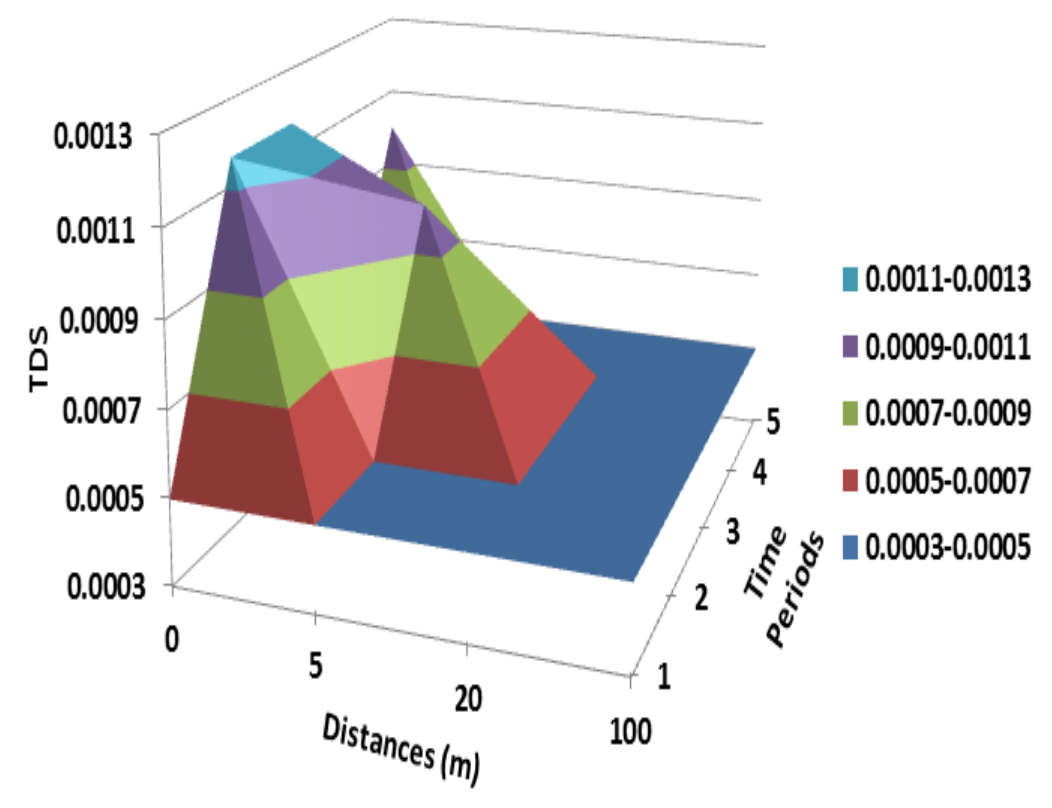

Figure 3: Surface Chart of average TDS of water at different distances for five time periods

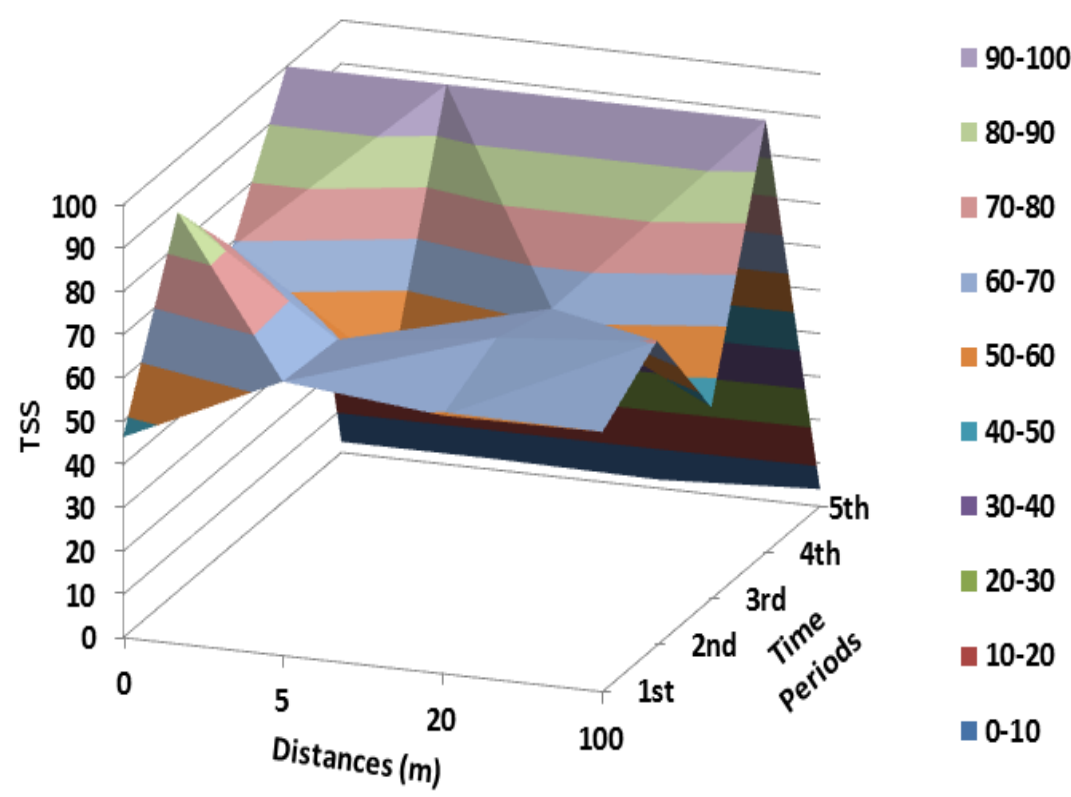

Figure 4: Surface Chart of average TSS of water at different distances for five time periods 


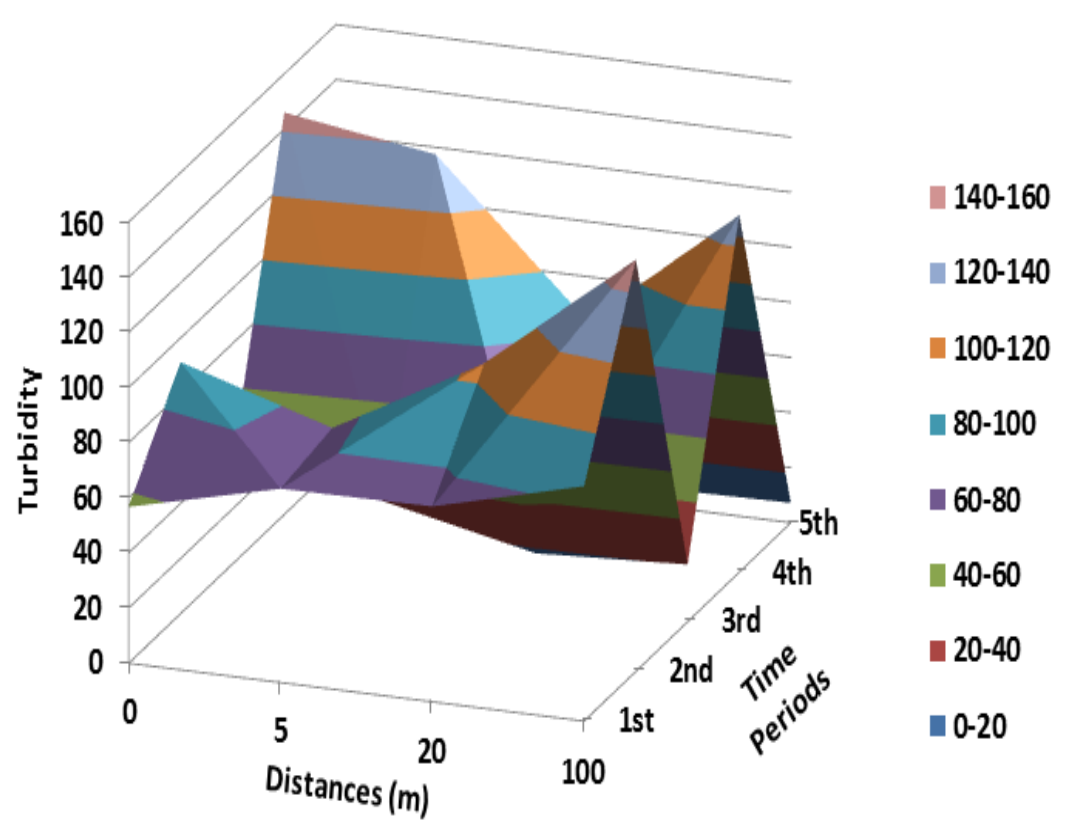

Figure 5: Surface Chart of average Turbidity of water at different distances for five time periods

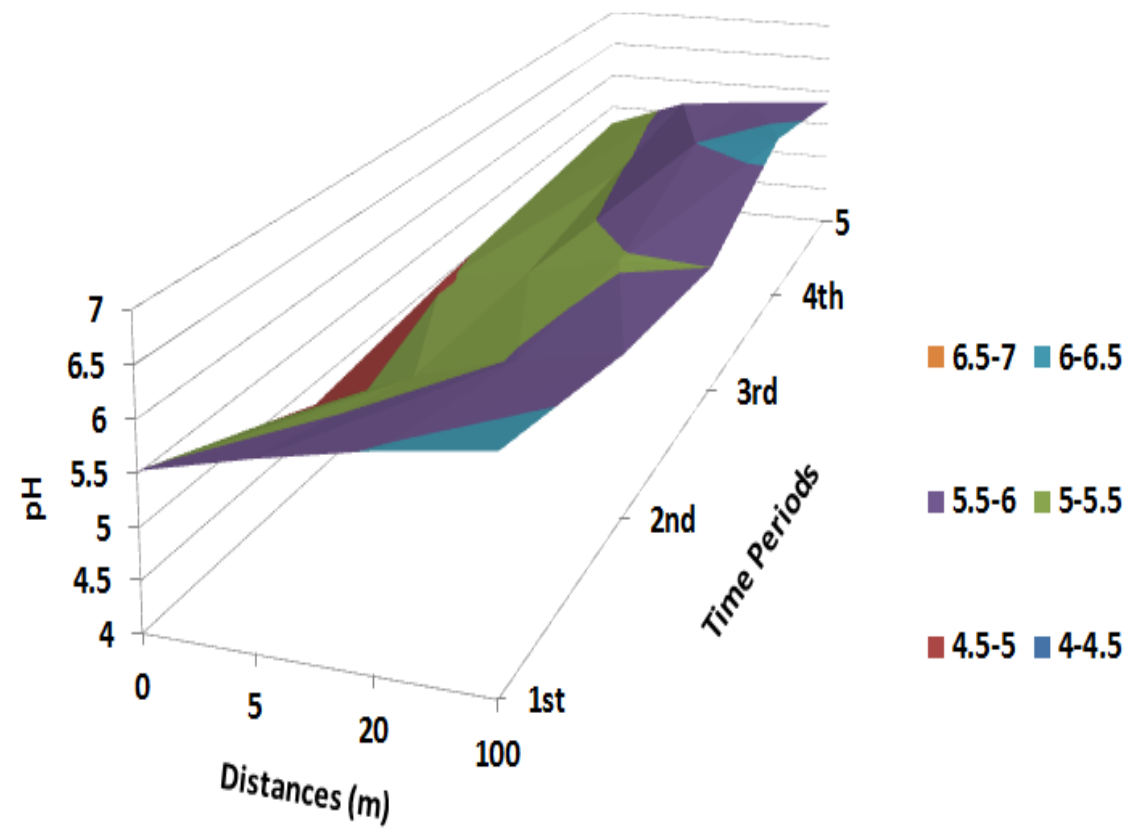

Figure 6: Surface Chart of average pH of water at different distances for five time periods 


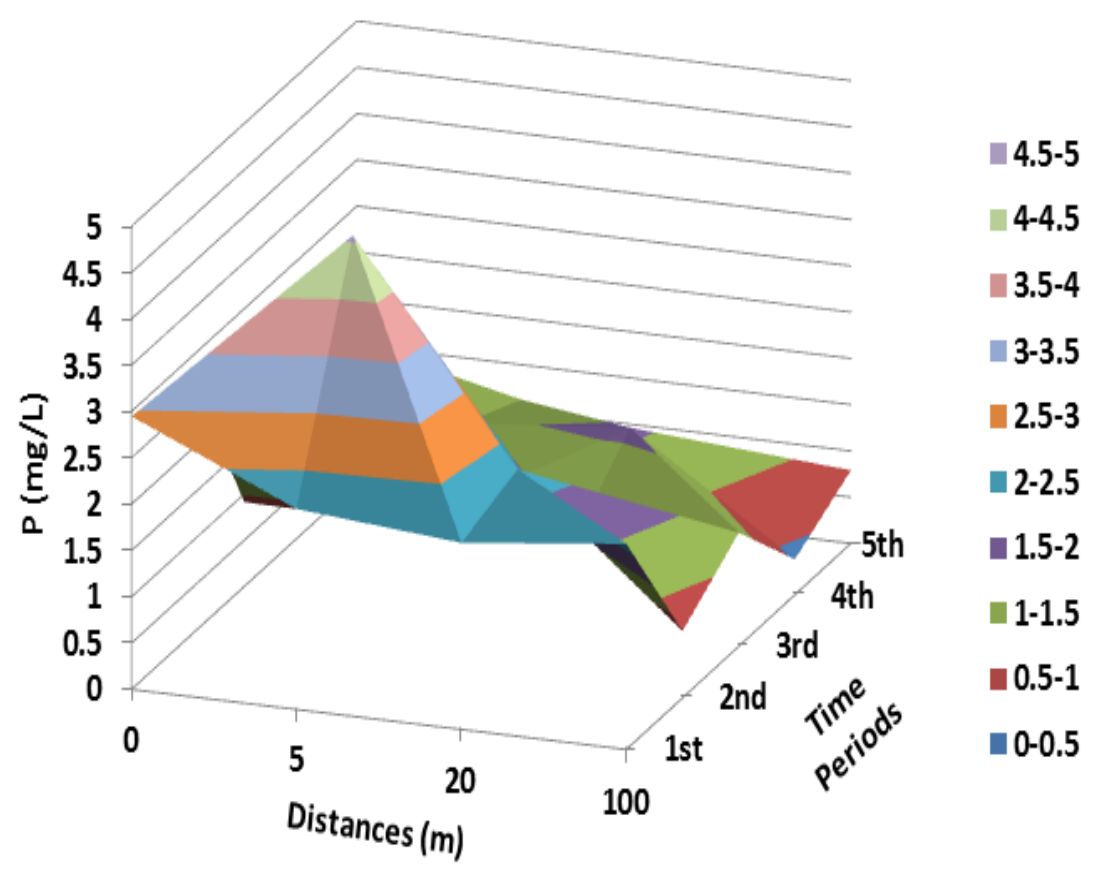

Figure 7: Surface Chart of average $P$ in water at different distances for five time periods

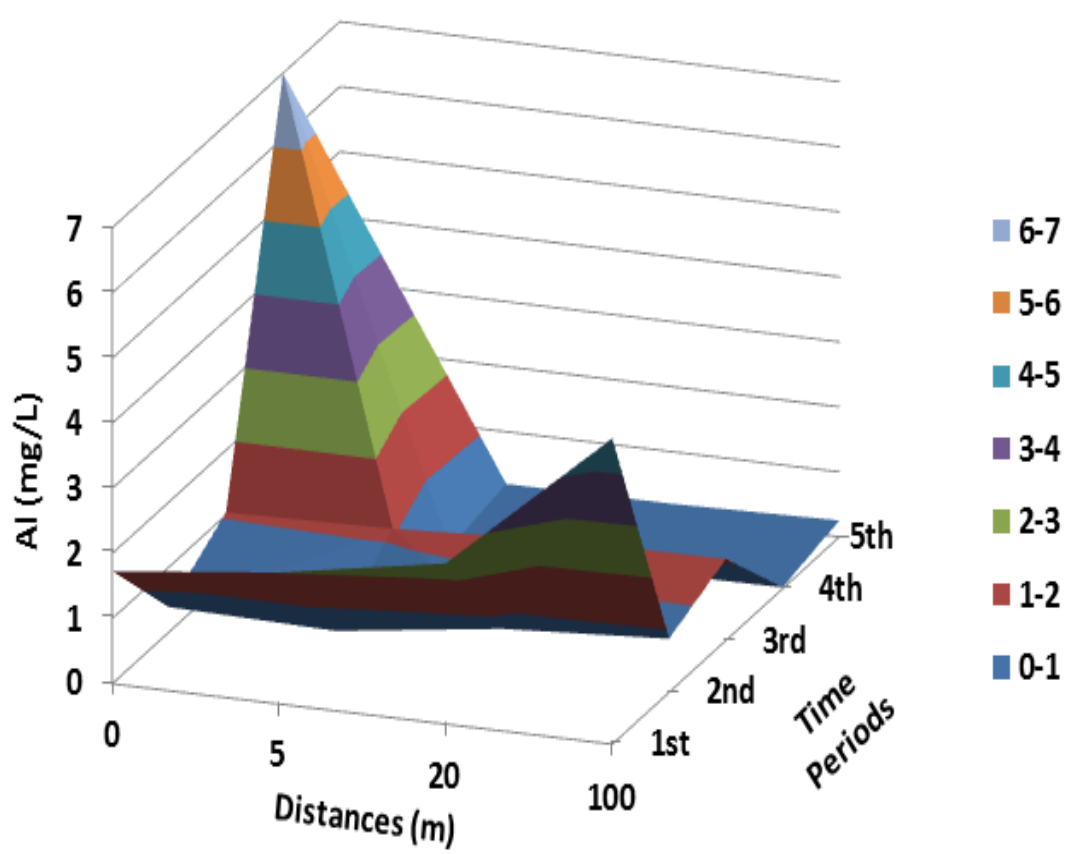

Figure 8: Surface Chart of average Al in water at different distances for five time periods 


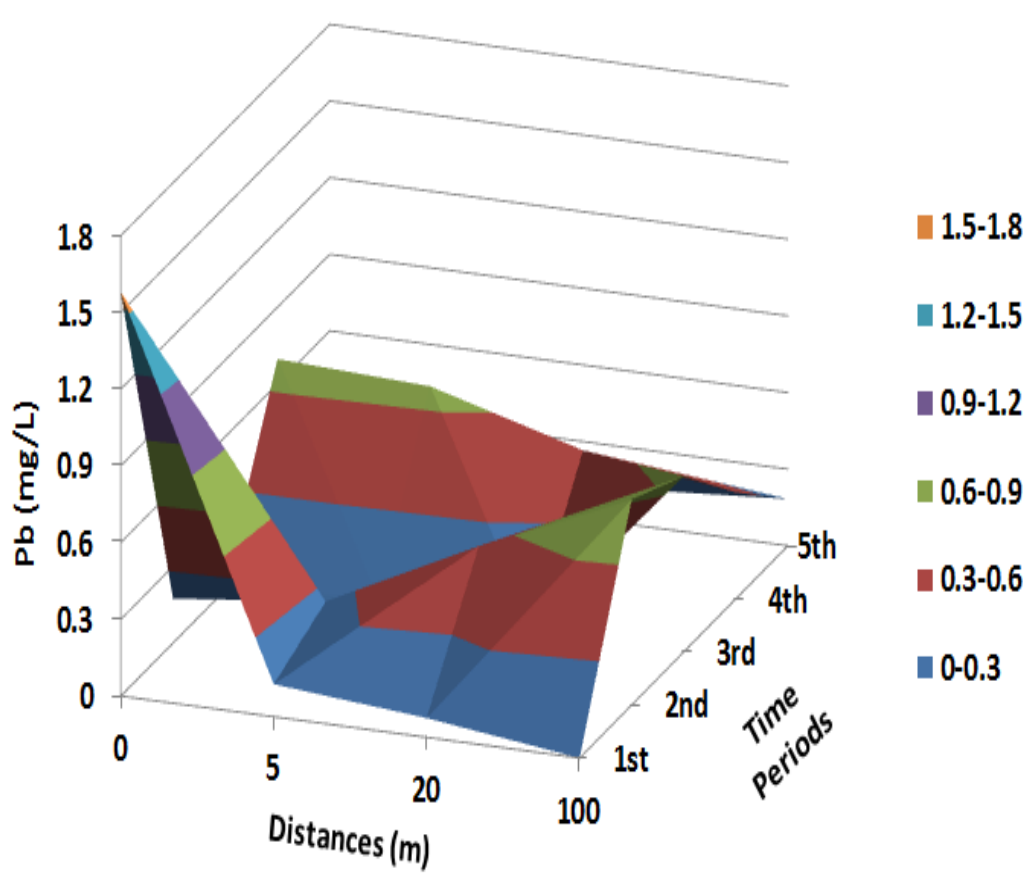

Figure 9: Surface Chart of average $\mathrm{Pb}$ in water at different distances for five time periods

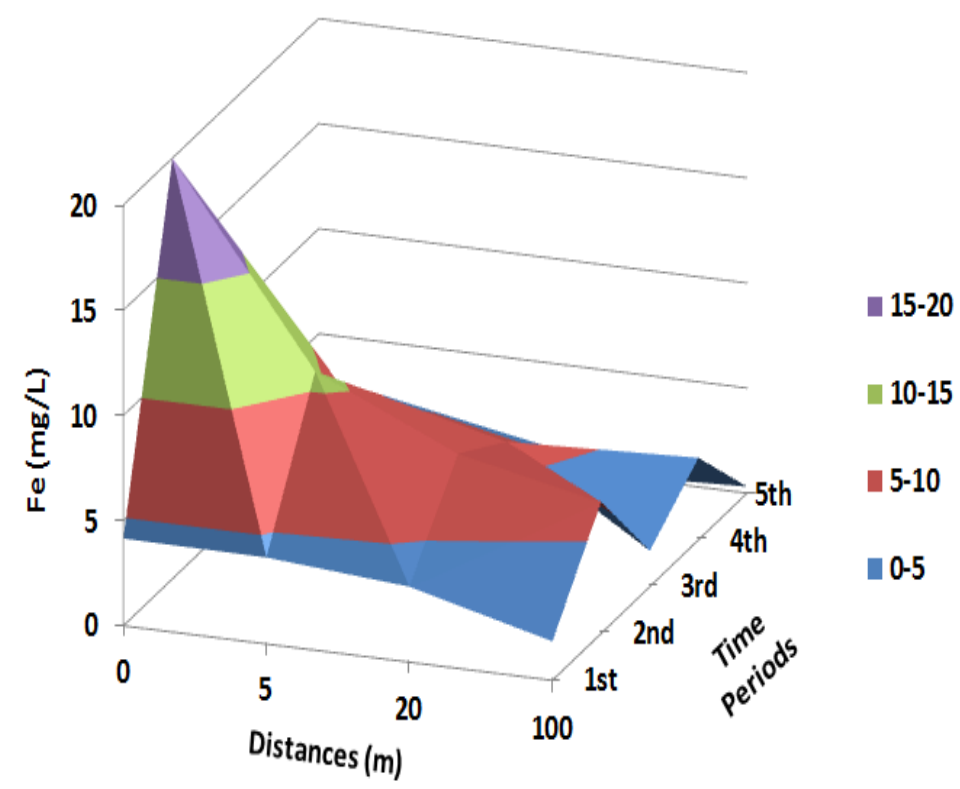

Figure 10: Surface Chart of average Fe in water at different distances for five time periods 


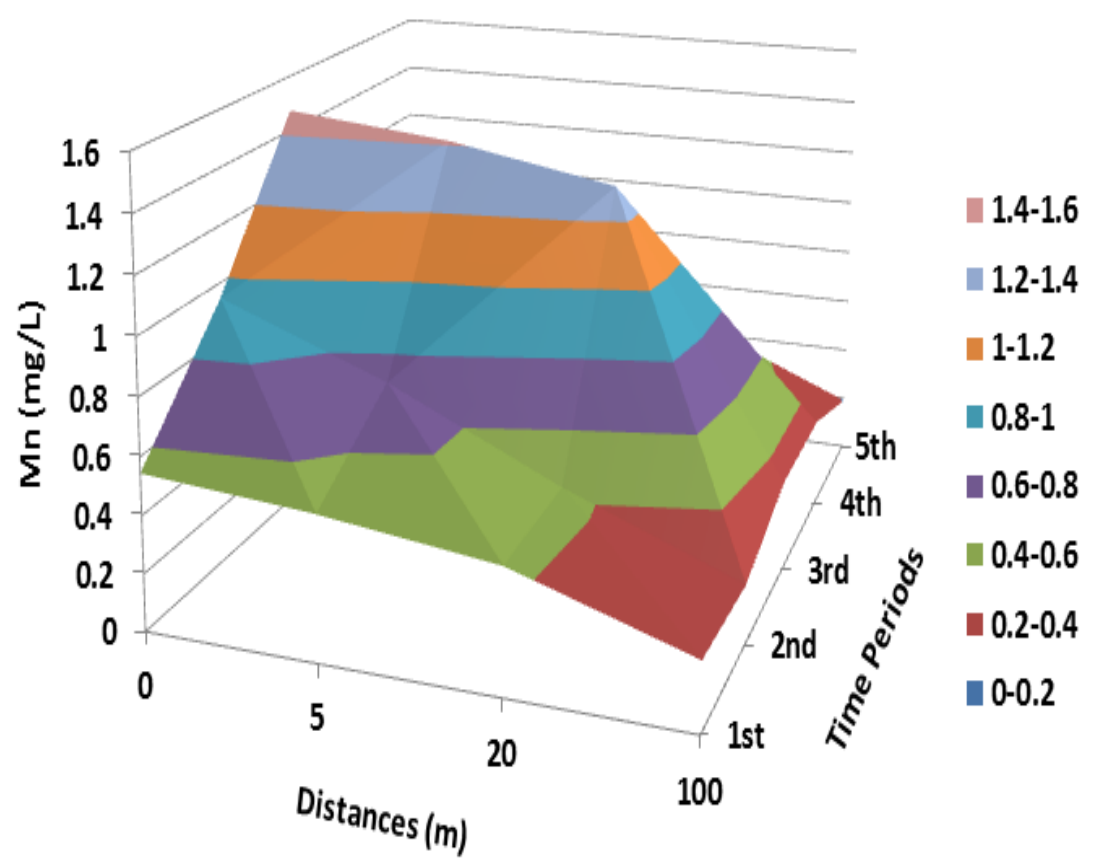

Figure 11: Surface Chart of average Mn in water at different distances for five time periods

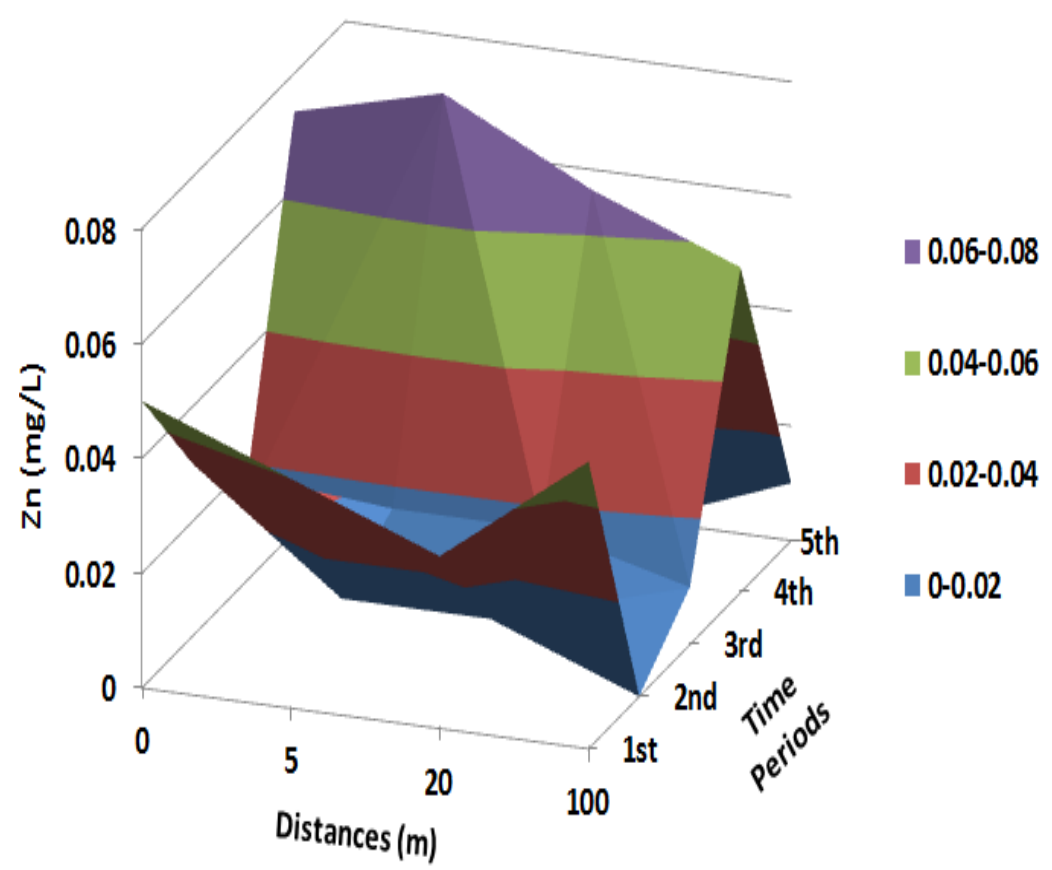

Figure 12: Surface Chart of average $\mathrm{Zn}$ in water at different distances for five time periods 


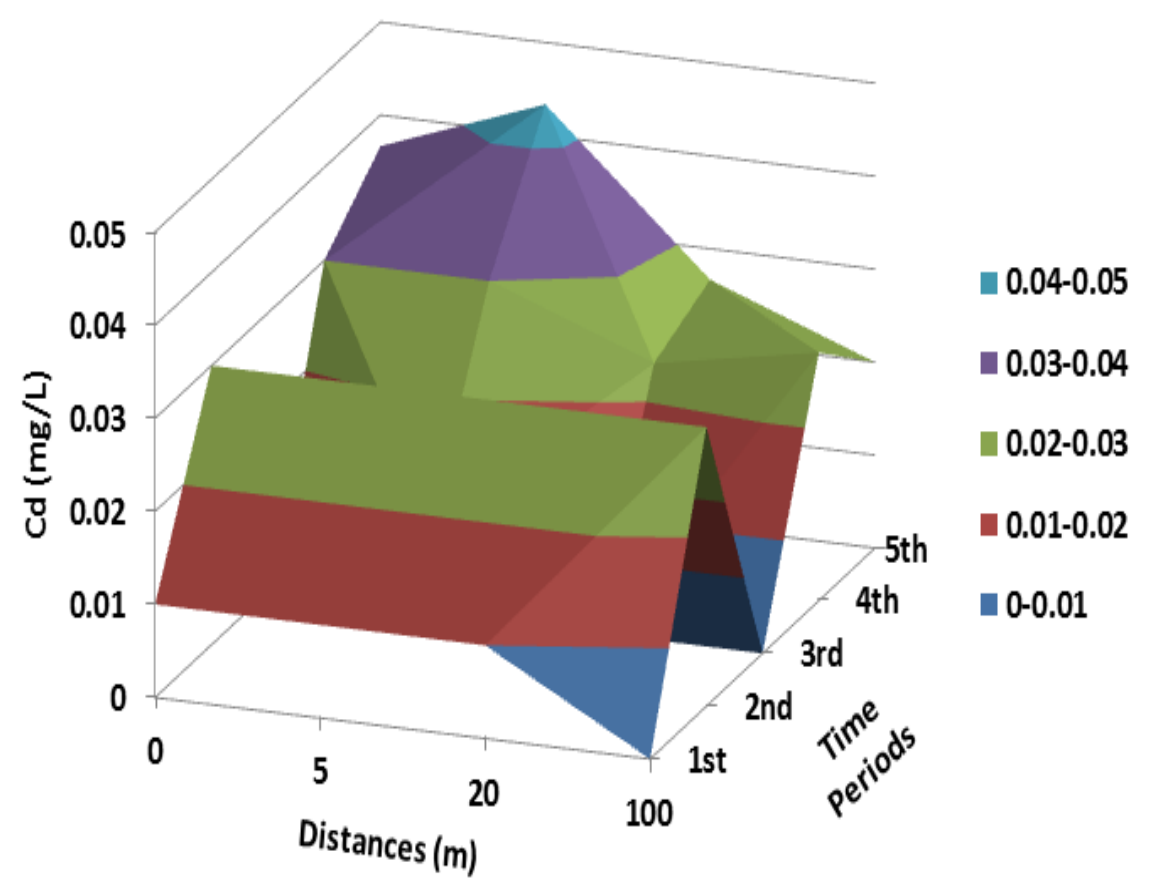

Figure 13: Surface Chart of average $\mathrm{Cd}$ in water at different distances for five time periods

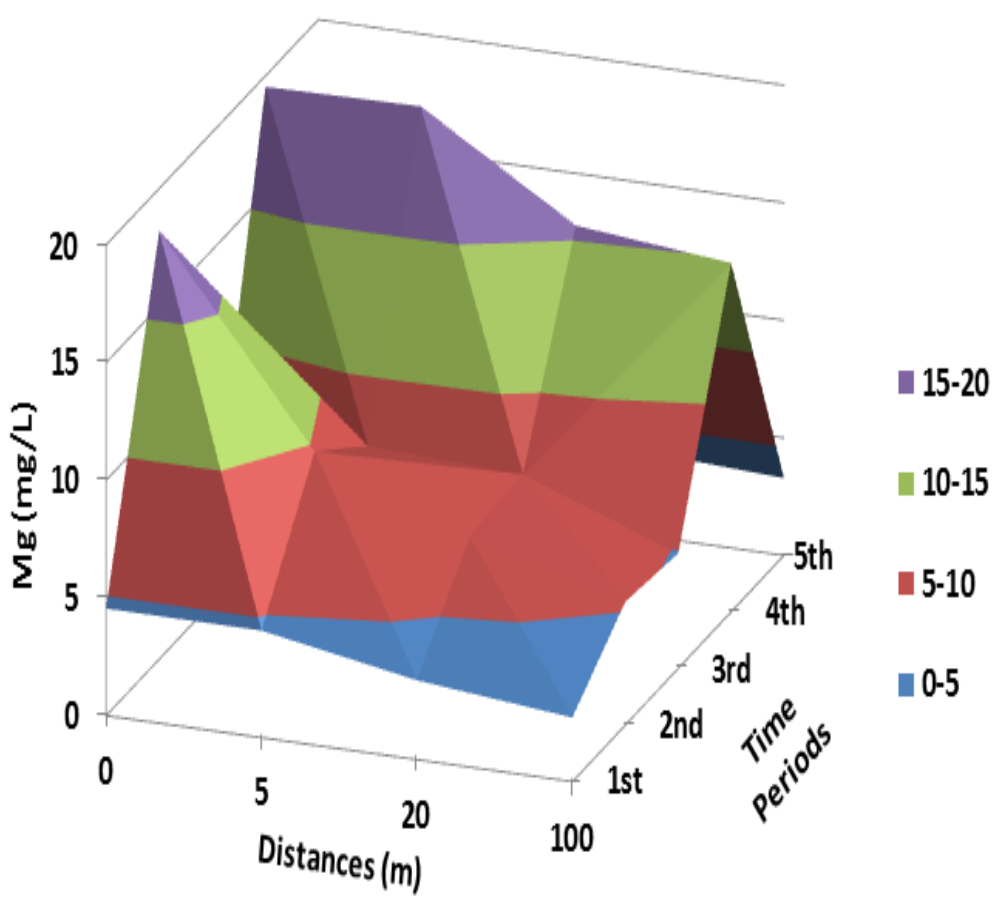

Figure 14: Surface Chart of average $\mathrm{Mg}$ in water at different distances for five time periods 


\section{Table 2: Concentration of various elements in the water at each distance for five time periods}

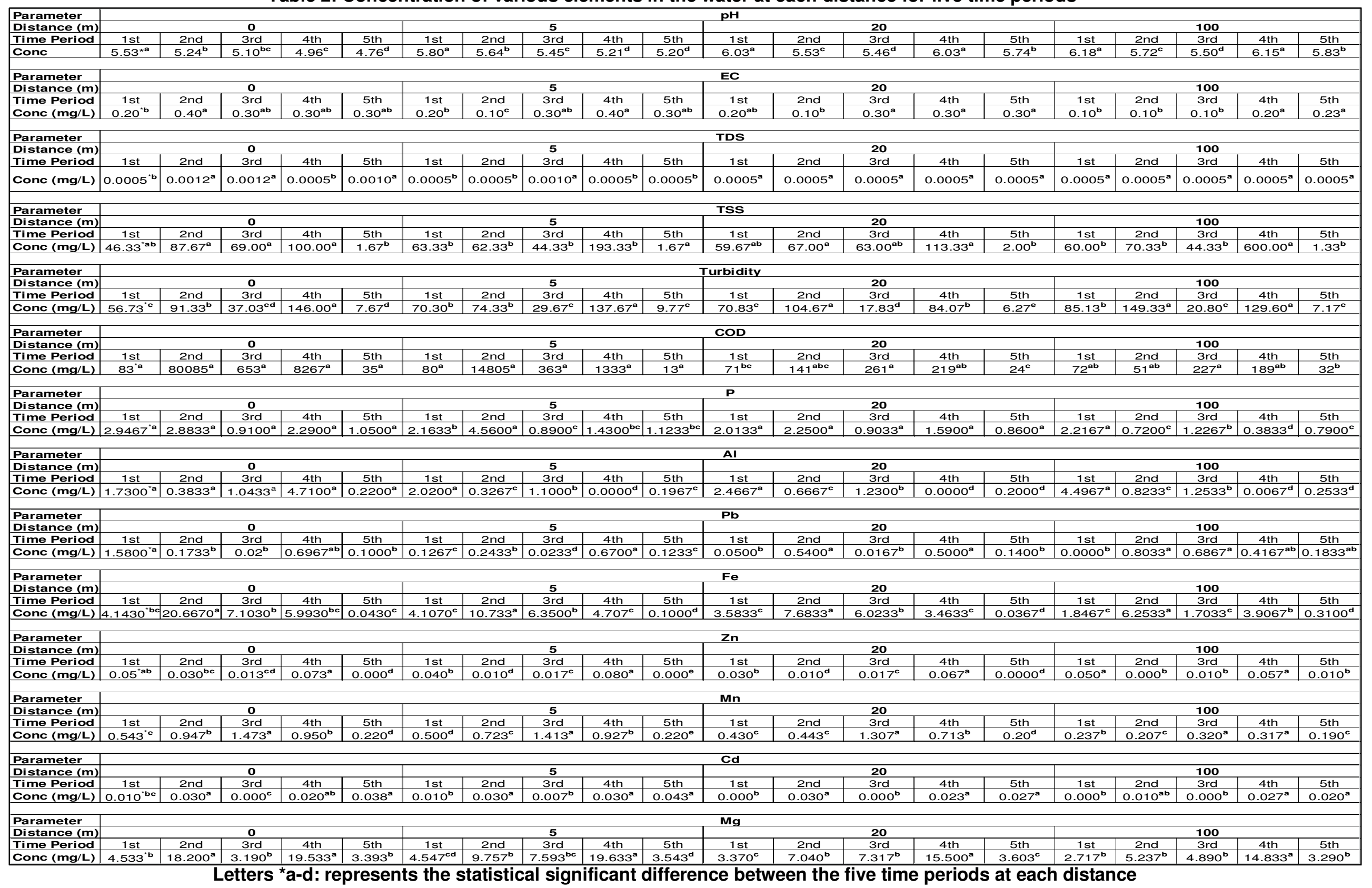




\section{DISCUSSION}

The $\mathrm{pH}$ and $\mathrm{EC}$ of vinasse produced at the Albion Bioethanol Plant compared favorably with those tested by Ahmed et al. (2012) and Vadivel et al. (2014). The other tested parameters varied with no distinct pattern in comparison with their studies (Table 1). Ahmed et al. (2012) and Vadivel et al. (2014) however noted that vinasse had high levels of COD, TSS, Al, Mn, Zn and Fe.

This study investigated spatial variability of the elements in the water channel over time at the point of effluent discharge, five metres, twenty metres and one hundred metres downstream from the point of discharge. Table 2 displays the concentrations of each parameter at the specific distances for the five time periods (two weeks before the plant commenced operations for the 2015 first crop, the day the plant commenced operations for that crop, one month and two months after the plant commenced operations, and approximately one week after completion of that crop season). The table shows the levels at each distance for the testing period which allows for examination of trends and relationships with respect to distance from discharge and time of operation.

There was no distinct trend with COD with regard to time periods, however was highest at the point of discharge, Figure 1. The COD levels in the canal were found to be relatively high. A high COD level is due to the soluble organic compounds that are present in the vinasse. Elevated COD concentrations can reduce the amount of dissolved oxygen in the water leading to hypoxia eventually causing disturbed cell functioning and even death of aquatic organisms.

The electrical conductivity observed was less than 0.4 (Figure 2) with no distinct change with distance or time. The electrical conductivity of a solution is directly proportional to the amount of salts present; organic matter and suspended solids do not contribute to its characteristics (Baez-Smith, 2006). This low EC can be attributed to poor conduction of electricity by the organic molecules in vinasse due to their inability to easily dissociate in aqueous solution. The TDS of the samples were relatively low and showed some level of consistency with respect to distance and time (Figure 3). TDS is a total amount of inorganic salts and a small amount of organic matter that is dissolved in the water. A low TDS indicates that the effluent indeed contains a high concentration of organic compounds.

For the Total Suspended Solids (TSS), a gradual increasing trend was observed with distance (Figure 4) and time, whilst there was no distinct trend with respect to turbidity (Figure 5). TSS refers to the total amounts of soil particles, organic matter, metals, and other materials that are suspended in a moving water course. Turbidity is the indication of water quality and is measured by the amount of light that is scattered in the water column. TSS can affect water quality tremendously with regards to light penetration and absorption; with greater TSS, the water absorbs more sunlight thereby reducing its ability to trap oxygen. With a higher light absorption and high turbidity (that is the reduction of the sun's penetrative ability), the penetrative ability is minimal and photosynthesis becomes an issue. This combined with depleted oxygen levels aids in a water course becoming uninhabitable to aquatic organisms.

The analyses revealed that the acidic effluent contributes greatly to a decreased $\mathrm{pH}$ level in the canal. The acidic nature of vinasse is attributed to the presence of carboxylic acids and the conversion of ethanol to ethanoic acid. It was found that the $\mathrm{pH}$ was much lower at the point of discharge and increased with distance also as time progressed the $\mathrm{pH}$ of the canal decreased gradually (Figure 6). This low $\mathrm{pH}$ creates a favourable medium for various chemical reactions involving other elements particularly heavy metals found in the vinasse. With a low $\mathrm{pH}$ there is increased competition with $\mathrm{H}+$ ions and dissolved metals for ligands. Additionally, with the acidic medium, the adsorption ability of the heavy metals decrease greatly and the mobility of such elements increases.

The analyses revealed that the phosphorus concentrations were varied with respect to distance and time (Figure 7) which may be due to interaction with other elements in the prevailing conditions. The phosphorus levels were found to be high and this can lead to eutrophication in the long term. Phosphorus has no direct reaction with water; however, under acidic conditions and low temperatures, this element reacts with heavy metals to form phosphides.

For majority of the heavy metals, the concentrations were high even before the plant commenced operations. This can be as a result of possible leaching of metallic components found in the factory. From the test, it was observed that the concentrations of these metals were greatest at the point of effluent discharge. Here the acidity of water provides a favourable environment for chemical reactions; however, due to the high organic matter content of the effluent, the dissolved oxygen levels will be very low. Many of these metals require oxygen to chemically react with water and under depleted oxygen levels, will not react but rather accumulate to very high levels as observed in the Table 2. Laboratory analyses were conducted for nitrates, copper, chromium, cobalt and nickel. However, these elements were not detectable within the water samples at the various sampling points.

Al showed a varying trend at the different distances throughout the sampling period (Figure 8). The acidity of the effluent aids in the increased solubility of $\mathrm{Al}$ in water and its reactivity. With the noted conditions, $\mathrm{Al}$ reacts with water to form a thin layer of aluminum oxide. When corrosion of this oxide occurs, the $\mathrm{Al}^{3+}$ ions undergo a chemical reaction where a highly flammable hydrogen gas is released. If the aluminum oxide is consumed by a biological 
system, upon assimilation, the Al poses adverse effects. In plants, it affects root development and hinders mineral intake, while in fishes it accumulates on the gills and eventually affects their breathing (Barabasz et al., 2002).

Similarly, $\mathrm{Pb}$ concentrations varied along the watercourse for the sampling. The $\mathrm{Pb}$ levels were relatively high at each point in the canal (Figure 9). Lead is not soluble in water and with time, the metal will amass to very toxic concentrations. Lead affects a plant's ability to synthesize chlorophyll thereby reducing photosynthesis. In humans, high concentrations of lead oxide cause nausea, anemia and chronic lead poisoning. This metal has also been recognized as a probable human carcinogen by the International Agency for Research on Cancer (Dierks, 2016).

With Fe, the concentrations decreased with distance; however with respect to time, the levels showed variations (Figure 10). These variations may be due to interaction with other elements. The study revealed that the Fe concentrations are very high in the canal.

Mn levels showed a general increase with time and a decrease with distance (Figure 11). This implies that as time progresses, the release of vinasse into the canal leads to a buildup of manganese. The accumulation and uptake of excessive amounts of $\mathrm{Mn}$ by humans can lead to neurotoxicity that causes serious neurological disorders (Crossgrove and Zheng, 2004).

The concentration of zinc varied along the watercourse for the sampling period. The levels were primarily high and eventually over time may become an issue (Figure 12). Zinc is not soluble in water and does not react; however, with time the metal may accumulate to very dangerous levels. The penetration of excessive amounts of zinc within the blood stream either orally or absorption through the skin can lead to copper deficiency with the body and accelerate the degeneration of brain cells (Plum et al., 2010).

Cadmium concentrations in the water course showed a varying trend with respect to distance and time (Figure 13). However, these concentrations were observed to be high and with accumulation such a metal may be detrimental to both plants and animals. The IARC (Dierks, 2016) has listed cadmium as a human carcinogen, concluding that increased levels in the human body leads to pneumonitis with intense fever, chest pain and pulmonary edema. Cadmium tends to remain in humans for long periods and may build up to very toxic levels. Likewise, in animals, it can bioaccumulate; in aquatic organisms such as shrimps and fishes it causes severe liver and brain damages. Cadmium adsorbs onto organic matter in the soil where it is taken up by plants and begins moving up the food chain, when these plants are consumed by animals.

With respect to magnesium, a general increasing trend was observed as the plant continued operations during the season. It was found that magnesium concentration was greatest at the point of effluent discharge with a general decreasing trend as distance from the plant increases (Figure 14). The magnesium toxicity varies depending on soil type and the nature of the crop (El-Jaoual and Cox, 1998) hence the accumulation may not be as detrimental as other metals.

The analyses have indicated that the acidity and high organic content of the vinasse aids in the accumulation and reactions of various heavy metals within the canal. With time and continuous disposal, these metals will amass to concentrations that will be detrimental to aquatic organisms and humans.

\section{CONCLUSION}

This study was conducted to investigate the spatial variability of elements due to the disposal of vinasse in the waterway surrounding the Albion Bioethanol Demonstration Plant. Water samples were taken at four (4) points downstream from the plant and the impact of vinasse discharge into the waterway way was assessed over a cropping season. It was determined that continuous disposal of vinasse in the waterway could result in the depletion of the oxygen supply and the accumulation of very toxic levels of heavy metals eventually causing the canal to become uninhabitable for aquatic life. Further, the impact could be detrimental to human life; hence it is recommended that studies be conducted on various techniques for the utilization and treatment of this effluent making it more environmentally friendly.

\section{REFERENCE}

Abrahim, BN., Clementson, C., and Homenauth, O. (2016). Assessment of the Potential Water Quality Effects Resulting from the Release of Vinasse, from the Bioethanol Demonstration Plant, into the Surrounding Waterway. Greener Journal of Agricultural Sciences 6(3): 102-109.

Ahmed, O., Sulieman, A., and Elhradallou, S. (2013). Physiochemical, Chemical and Microbiological Characteristics of Vinasse, A By-product from the Ethanol Industry. American Journal of Biochemistry 3 (3): 80-83. 
American Public Health Association, A. W. (1999). Standard Methods for the Examination of water and Wastewater Part 1000. http://www.mwa.co.th/download/file_upload/SMWW_1000-3000.pdf.

Baez-Smith, C. (2006). Anaerobic Digestion of Vinasse for the production of Methane in the Sugar Cane Distillery. Sugar Processing Research Institute Conference on Sugar Processing, Brazil, pp 268-287.

Barabasz, W., Albinska, D., Jaskowska, M., and Lipiec, J. (2002). Ecotoxicology of Aluminium. Polish Journal of Environmental Studies 11(3): 199-203.

Christofoletti, C., Escher, J., Correia, J., Marinho, J., and Fontanetti, C. (2013). Sugar cane Vinasse: Environmental Implications of its use. Waste Management 33(12): 2752-2761.

Crossgrove, J., and Zheng, W. (2004). Manganese Toxicity upon Overexposure. Nuclear Magnetic Resonance in Biomedicine 17(8): 544-553.

Dierks, S. (2016). ESPI Metals. Retrieved 04 27, 2016, from Lead Oxide: http://www.espimetals.com/index.php/msds/154-lead-oxide

El-Jaoual, T. and Cox, D. (1998). Magnesium toxicity in plants. Journal of Plant Nutrition 21(2): 353-386.

Habeeb, M., Al-Berman, A.-K., and Salman, J. (2015). Environmental study of water quality and some heavy metals in water, sediments and aquatic macropytas in lotic ecosystem, Iraq. Mesopotamia Environmental Journal 1(2): 66-84.

Haiyan, L., Shi, A., Li, M., and Zhang, X. (2013). Effect of pH, Temperature, Dissolved Oxygen, and Flow Rate of Overlying Water on Heavy Metals Release from Storm Sewer Sediments. Journal of Chemistry 2013: 1-11.

Pereira, S., and Pereira, P. (2008). Environmental Aspects in Ethanol production Related to Vinasse Disposal and Groundwater. International Geological Congress. Brazil.

Plum, L. M., Rink, L., and Haase, H. (2010). The Essential toxin: Impact of Zinc on Human Health. International Journal of Environmental Research and Public Health 7(4): 1342-1365.

Vadivel, R., Minhas, P., Kumar, S., Singh, Y., Nageshwar, R., \& Nirmale, A. (2014). Significance of Vinasse Waste Management in Agriculture and Environment. African Journal of Agricultural Research 9 (38): 2862-2873.

Cite this Article: Clementson C, Abrahim BN, Homenauth O (2016). An Investigation of the Spatial Variability of Elements Due to Vinasse Disposal in Waterways at the Albion Bioethanol Plant, Berbice Guyana. Greener Journal of Environmental Management and Public Safety, 5(3):074-087, http://doi.org/10.15580/GJEMPS.2016.3.071916120 